\title{
CRACK PROPAGATION IN POST-CORE REHABILTATION OF A MAXILLARY CENTRAL INCISOR AFTER ROOT RECONSTRUCTION
}

\author{
E. B. de Las Casas ${ }^{1}$, O. L. Manzoli ${ }^{2}$, C. M. A. Mattos ${ }^{3}$ \\ ${ }^{1}$ Department of Structural Engineering, PosEEs, PPGMEC, Universidade Federal de Minas \\ Gerais, Belo Horizonte, Brazil (estevam @ dees.ufmg.br) \\ ${ }^{2}$ Department of Civil Engineering, UNESP - São Paulo State University, Bauru, Brazil \\ ${ }^{3}$ Doctoral Student, PPGMEC, Universidade Federal de Minas Gerais; Assistant Professor, \\ Dental School, Universidade Federal do Espirito Santo, Vitoria, Brazil
}

\begin{abstract}
Prosthetic rehabilitation of endodontically treated teeth usually requires the use of an endodontic post and coronal core to enhance artificial crown retention. In cases of flared canals, the weakened remaining dentin walls have to be reconstructed prior to post insertion in order to increase post retention and root strength. The use of adhesive composite resin restorative materials is usually recommended. Based on the mechanical resistive properties of dentin and restorative materials found in the literature, this study describes a numerical predictive analysis of crack propagation which may lead to fracture after root reconstruction. A $3 D$ finite element model of a maxillary central incisor restored with a glass fiber post/composite core/crown system was constructed. The root canal walls were thinned to simulate a root defect filled by adhesive composite resin. A $100 \mathrm{~N}$ oblique load was applied to the crown lingual surface, simulating normal mastication. The possibility of crack formation followed by dentin root wall fracture or disruption of the cement layer was investigated. A scalar damage model based on the maximum principal stress criterion was used to predict crack propagation. The parameters of the constitutive model were the elastic properties, the tensile strength and the fracture energy of the material.
\end{abstract}

Keywords: Failure analysis, Crack propagation, Interfaces, Dental biomechanics, Endodontic Posts.

\section{INTRODUCTION}

Clinical and experimental studies have shown that endodontically treated teeth are more prone to root fracture $[1,2]$. This may be attributed mainly to structural loss caused by carious lesions, trauma and extensive restorations, which progressively decrease the tooth resistance and rigidity [3-5]. These teeth require major prosthetic reconstructions resulting in complex systems composed by an endodontic post, a coronal core and an artificial crown [6]. 
Although it may be necessary for the crown retention, placing a post inside the root canal generates an additional risk, because the oclusal load is then transmitted directly to the root walls $[7,8]$.

The clinical situation becomes more critical when the residual root walls are extensively damaged, as in cases of caries reaching the root canal, excessive endodontic instrumentation, or previous use of large posts [9]. This type of thin walled root may compromise the success of the restoration outcome. The use of adhesive restorative materials with mechanical properties similar to those of dentin to increase the internal root width has been suggested for reconstruction of weakened root walls [10-14]. This concept has been generally named "monoblock restorations" $[10,11]$.

However, restorative systems are not able to fully recover the level of resistance of intact roots [15-17] and mechanical failures of these teeth may lead to microleakage, recurrent caries, crack formation and root fractures $[1,9,18]$.

Experimental studies show that weakened roots tend to fail at the cervical region $[11,17]$ and finite element studies have confirmed the presence of stress peak areas at this location [19]. Failure usually occurs when the stress levels reach the ultimate stress of dentin or restorative materials, but the role of the multiple interfaces as a possible source of structural failure must not be ignored in such a complex restorative system. Besides the fracture strength, also the bond strength between these materials and the root dentin walls must be taken into account.

From a mechanical point of view, a post/core/crown restored tooth can be considered a structure formed by multiple components with a complex geometry [20]. Clinically, the failure of these restorative systems will occur in the form of root fracture or post dislodgement [21-23].

In this work a finite element analysis (FEA) is described to evaluate the risk of damage in weakened roots of endodontically treated teeth after adhesive composite root reconstruction. According to the resistive properties of the dentin and the restorative materials, a predictive analysis of the probable failure modes (root fracture, post dislodgement) and their locations was performed. This approach was first proposed for the study of concrete structures [24] and was experimentally applied to tooth structural damage in this study.

\section{METHODS}

Ansys ${ }^{\circledR} 12.0$ (Canonsburg, PA, USA) was used for preprocessing. The 3D model simulated an endodontically treated maxillary central incisor with a cervical root defect that had been prosthetically reconstructed by means of composite resin, glass fiber post and a full metal crow (Fig. 1). The cervical root reconstruction followed the anatomic post technique [13], where the reconstruction is cemented inside the weakened root to avoid problems like difficult access for the curing light and composite resin polymerization contraction. The post was modeled comprising the two thirds of the root length, leaving $4 \mathrm{~mm}$ of guta-percha at the root apex for endodontic sealing. Resin cement layer was modeled within a width of $100 \mu \mathrm{m}$ surrounding the post wall and the composite reconstruction. A perfect and continuous 
adhesion was assumed between the post/cement and cement/dentin interfaces. The model involved tooth structures, periodontal ligament, cortical and trabecular bone.

Table 1 describes the elastic constants of the materials represented in the finite element model [19]. The model was discretized in a tetrahedric element mesh, with 28036 nodes and 156298 elements. During the mesh convergence test, a $100 \mathrm{~N}$ load was applied on the palatal surface at an angle of $130^{\circ}[25]$ from the long axis of the tooth and analysis was performed at each point for maximum and minimum principal stresses ( $\sigma_{1}$ or $S 1$; $\sigma_{3}$ or $\left.S 3\right)$.

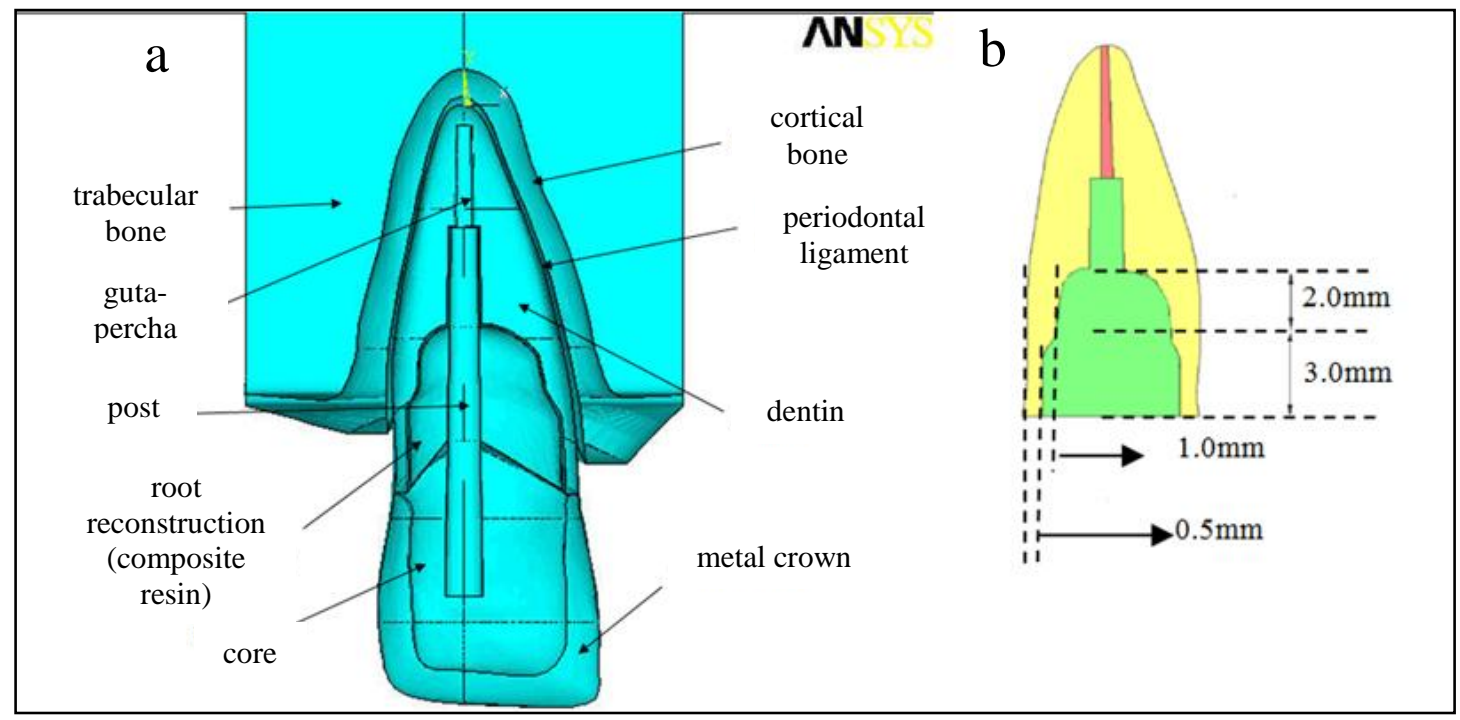

Fig. 01: Geometric model (a); geometry and size of the root defect (b).

After discretization, a scalar damage model based on the maximum principal stress criterion was used to predict crack propagation. The parameters of the constitutive model were the elastic properties, tensile strength and fracture energy of the material (Tables 1 and 2). A rate-independent isotropic constitutive model originally developed for the numerical analysis of concrete structures was applied [24]. In this format, with the aim of creating a scalar damage model, the internal damage variables for tensile and compressive stress contributions are analyzed separately in a split of the effective stress tensor into independent tensile and compressive components. According to this stress splitting, the proposed constitutive law is given in equation (1):

with

$$
\sigma=\left(1-d^{+}\right) \bar{\sigma}^{+}+\left(1-d^{-}\right) \bar{\sigma}^{-} \text {. }
$$

$$
0 \leq d^{+} \leq 1 \text { and } 0 \leq d^{-} \leq 1
$$

where $\mathrm{d}+$ and $\mathrm{d}-$ are the tensile and compressive damage variables, respectively, and $\bar{\sigma}^{+}$and $\bar{\sigma}^{-}$are the tensile and compressive parts of the effective (elastic) stresses. The damage variables can be ranked from zero to one, where zero indicates no damage (intact material) and one represents fully damaged material. 
In this study, only the tensile stresses and damage were considered for the analysis of the risk of damage within the reconstructed root. The damage variable evolution is related to a softening law (reduction of stresses with increasing strains), which is defined in terms of the tensile strength and the fracture energy of the material. During this analysis, all the nodes on the external surface of the root were constrained in all directions.

Table 1. Elastic constants of biological and restorative materials. E: Elastic modulus, $v$ : Poisson ratio.

\begin{tabular}{|c|c|c|c|c|}
\hline MATERIAL & \multicolumn{2}{|c|}{ E (GPa) } & \multicolumn{2}{|c|}{$v$} \\
\hline $\begin{array}{l}\text { Composite resin (Filtec Z250-3M } \\
\text { ESPE, MN, USA) }\end{array}$ & \multicolumn{2}{|c|}{10.49} & \multicolumn{2}{|c|}{0.30} \\
\hline \multirow{2}{*}{$\begin{array}{l}\text { Glass fiber post (FibreKor-Pentron } \\
\text { Clinical Technologies-CT, USA) }\end{array}$} & $\mathrm{E}_{x}$ & $\mathrm{E}_{y} \mathrm{e} \mathrm{E}_{z}$ & $x$ & $y$ e $z$ \\
\hline & 40.0 & 9.5 & 0.34 & 0.27 \\
\hline $\begin{array}{l}\text { Ni-Cr alloy (UniMetal Shofu Inc., } \\
\text { Kyoto, Japan) }\end{array}$ & \multicolumn{2}{|c|}{203.6} & \multicolumn{2}{|c|}{0.30} \\
\hline $\begin{array}{l}\text { Resin cement (Rely X Arc-3M } \\
\text { ESPE, MN, USA) }\end{array}$ & \multicolumn{2}{|c|}{5.5} & \multicolumn{2}{|c|}{0.24} \\
\hline Gutta percha & \multicolumn{2}{|c|}{0.14} & \multicolumn{2}{|c|}{0.4} \\
\hline Dentin & \multicolumn{2}{|c|}{18.45} & \multicolumn{2}{|c|}{0.29} \\
\hline Periodontal ligament & \multicolumn{2}{|c|}{$0.31 \mathrm{e}-04$} & \multicolumn{2}{|c|}{0.45} \\
\hline Cortical bone & \multicolumn{2}{|c|}{11.17} & \multicolumn{2}{|c|}{0.45} \\
\hline Trabecular bone & \multicolumn{2}{|c|}{$9.62 \mathrm{e}-02$} & \multicolumn{2}{|c|}{0.30} \\
\hline
\end{tabular}

Table 2: Resistive properties of the structures considered in the analysis.

\begin{tabular}{lccc}
\hline & Dentin & $\begin{array}{c}\text { Composite } \\
\text { resin }\end{array}$ & $\begin{array}{c}\text { Cement/ dentin } \\
\text { interface }\end{array}$ \\
\hline $\begin{array}{l}\text { Ultimate tensile } \\
\text { strength }(\mathrm{MPa})\end{array}$ & 63.2 a $95.9[26]$ & $39[27]$ & $16-17[28]$ \\
\hline $\begin{array}{l}\text { Energy to fracture } \\
\left(\mathrm{J} / \mathrm{m}^{2}\right)\end{array}$ & $742[29]$ & $550[30]$ & $75[31]$ \\
\hline
\end{tabular}

A load factor varying from 1 to 5 was used, corresponding to a 100 to $500 \mathrm{~N}$ load applied to the palatal surface of the reconstructed tooth. Although normal chewing forces may range from 89-240 N [32], due to its large variability among individuals, a 300N load has been reported in order to carry out a clinically relevant study [33].

The risk of damage was analyzed separately and analysis focused on the fracture tensile strength of dentin and on the bond strength between dentin and cement, because these are the most commonly observed areas of clinical failure [23]. Partial or complete ruptures in the adhesive interfaces affect the monoblock function of the restoration.

Finite elements with high aspect ratio have been used to model the interface between dentin and cement, following the approach proposed by Manzoli et al. (2012) [34]. The degradation failure process of this interface is also described by the scalar tensile damage 
model. The assumed values of the tensile strength and fracture energy of the interface are presented in Table 1.

\section{RESULTS}

Figures 2-4 show the damage behavior of the reconstructed root structures, with a tensile damage factor varying from 1 to 5 . The risk of damage in root dentin buccal walls is shown in Figure 2, assuming a perfectly bonded interface. Damage begins to appear with a damage factor 3. In Figure 3, damage to adhesive interface was simulated. With the failure of the adhesive dentin/cement interface, stresses in the root walls decreased and a quite large load factor $(\mathrm{F}=4)$ was required to cause damage to dentin structure. Figure 4 highlights the damaged interface area. The risk of damage was rated on a 0 (no risk) to 1 (damage) scale.

\section{DISCUSSION}

Although long-term functional survival rates can be high for endodontically treated permanent teeth, they are generally more susceptible to fracture than vital teeth. Tooth extraction is often the consequence of an unfavorable prognosis after coronal and root fractures, but its occurrence in endodontically treated teeth might be reduced by identifying the risks for fracture associated with various operative procedures [35].

Human dentin is a structural mineralized tissue with a brittle behavior [36] and therefore less resistant to tensile (95,9MPa) [26] than compressive stresses (297MPa) [37]. Although different failure criteria are used for the analysis of the mechanical behavior of tooth structures, it was assumed that a failure criterion based on the maximum tensile stresses would be the most appropriate. The risk of damage caused by tensile stresses appears in the cervical third of the root buccal wall, although this is a typical location of compressive stresses in maxillary anterior teeth [38-41]. This behavior can be explained as a consequence of the effect of circumferential tensile stresses concentrated on the buccal root wall. When the compressive load applied on the palatal surface is transferred to the buccal root walls by the post and composite resin, compressive stresses in a radial direction tend to appear resulting in deformation of the buccal root wall. The root walls expansion creates additional circumferential internal tensile stresses resulting from the outward bending of the dentin wall [42].

In order to visualize the damage to the dentin root walls, two different situations were analyzed separately. In Figure 2, the interface was kept intact by attributing a high fracture strength. In Figure 3, localized failures of the cement/dentin interface were simulated and the dentin walls response was analyzed. This procedure was carried out to demonstrate the effect of the interface disruption in relation to an intact one.

In Figures 2 and 3 some damage can be observed on the cervical root wall, corresponding to the area involving the reconstructed root defect. This location is consistent with the presence of compressive stresses (S3) found in a numerical analysis of the biomechanical behavior of a weakened root after adhesive reconstruction and post-core rehabilitation [19]. The damage not necessarily implies in fracture of the root, but small 
cracks may have been formed inside the root wall. Crack propagation is associated to longterm fatigue root fracture upon functional cyclic loading [22, 43, 44]. Based on the fatigue crack growth mechanism, a pre-existing flaw of sufficient size (approximately 0.3-1.0 mm) can grow to catastrophic proportion with cyclic loading at stresses below $30 \mathrm{MPa}$ [45]. The teeth, cement and reconstruction are all subjected to cyclic stress generated by oclusal forces, and fatigue fracture may occur at the weakest point or where the maximum stress occurs [46]. In this particular case, the maximum stresses are located at the cervical third.

In this analysis, a perfect and continuous adhesion was assumed on the cement/dentin interface. When this interface is locally damaged (Fig. 3 and 4), adhesion is impaired and, although the two structures return to work in contact, a major damage factor is required to injury the root wall structure. This fact indicates that the magnitude of the stresses in dentin walls decreases after local disruptions of the adhesive interface without post dislodgments. Therefore, incomplete localized failures restricted to the interface in highly stressed areas may have a protective effect on the dentin root walls.

With the use of fiber posts, the stress concentration is located at the post-cement interface and in the cement bulk, preserving root dentine from dangerous stress accumulation [47]. The use of higher elastic modulus cements creates higher stress levels within itself [48] decreasing the stress peak values in dentin [49]. It is known that the conventional nonadhesive post cementation is less reliable to withstand simulated functional forces compared to adhesive approaches [50] and that resin composite cement is most likely to resist clinical failures [51]. However, although the practical benefits of resin-hard-tissue adhesion are easily demonstrable [31], these preliminarily results suggest that it would be advisable to use less resistant cements than conventional resin cements [52] or with lower bond strengths [53], benefiting from the adhesive properties but protecting dentin at the same time. This could be achieved by using a resin modified glass ionomer luting cement, with the additional advantage of fluoride release [54]. Further experimental studies would be necessary to confirm these findings.

Geometric parameters vary among the populations, from one individual to another. In addition, other factors such as age, location, occlusion and masticatory loads may affect the tooth mechanical behavior. When studying biological structures, it must be kept in mind that the numerical results will refer to that specific situation simulated by the FEA model and may need further evidence to be extrapolated to outside the context of the model assumptions [55].

Great variability can also be observed concerning the mechanical properties of dentin and dental materials in the literature. In the case of dentin, this fact can be attributed to the possibility of undetectable defects inside test specimens $[45,56]$, to different degrees of mineralization and to its anisotropic behavior, as a consequence of the internal configuration of the dentinal tubules [26]. Different methodological designs have been related as the main reason for inconsistencies on the dental material properties reported by different authors [57]. This variability associated with the mechanical parameters may lead to uncertainties on the numerical results of FEA studies. A parametric study would be desirable to check the role of each of these variables. 

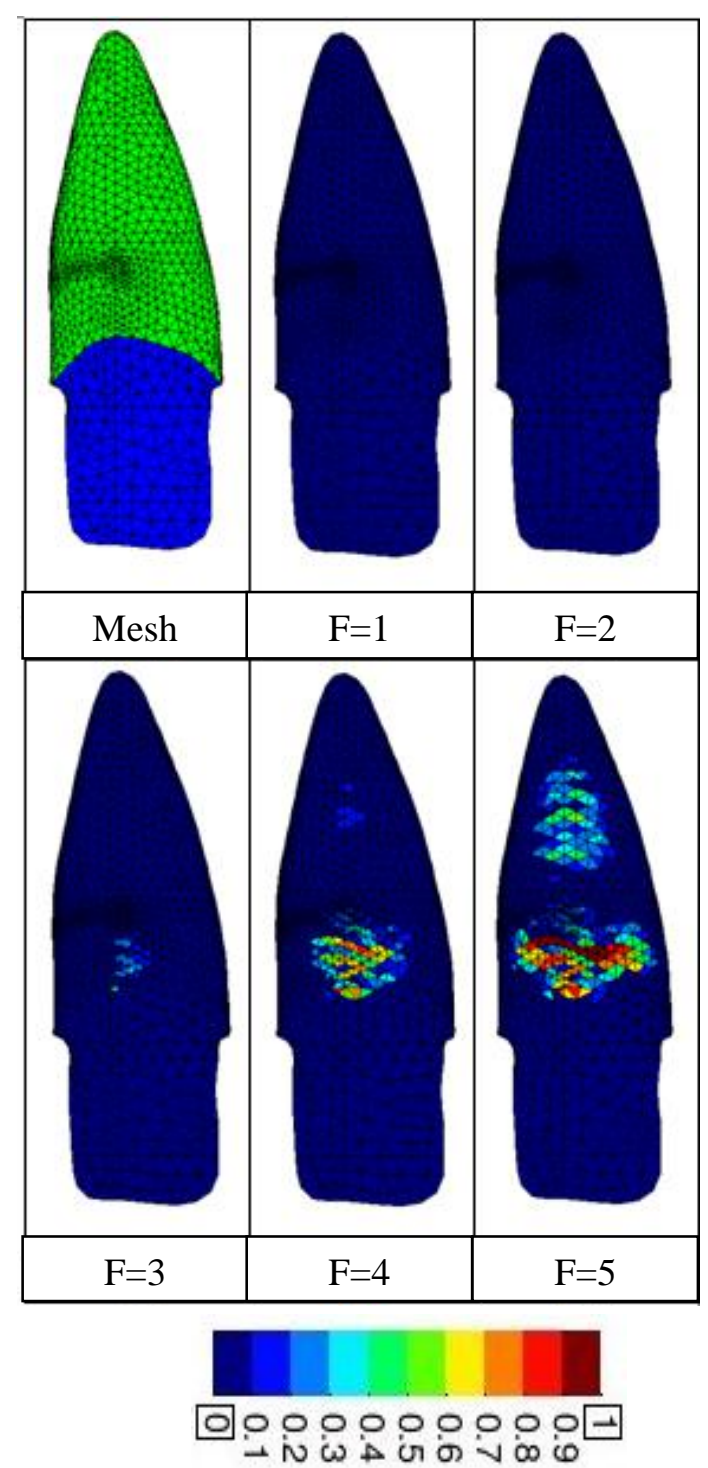

Fig 2.: Tensile damage on the buccal root walls considering an intact interface.

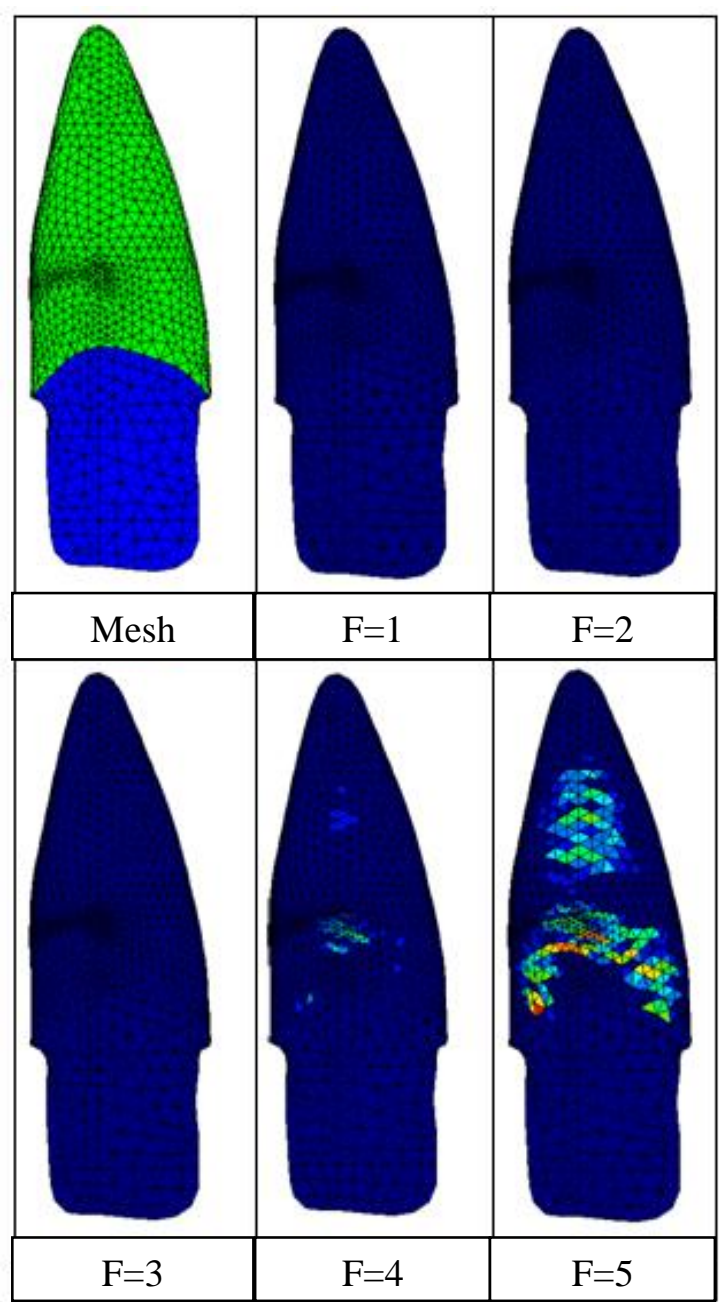

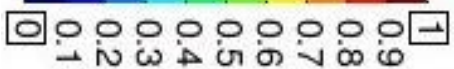

Fig 3.: Tensile damage on the buccal root walls considering failure of the bonded interfaces.

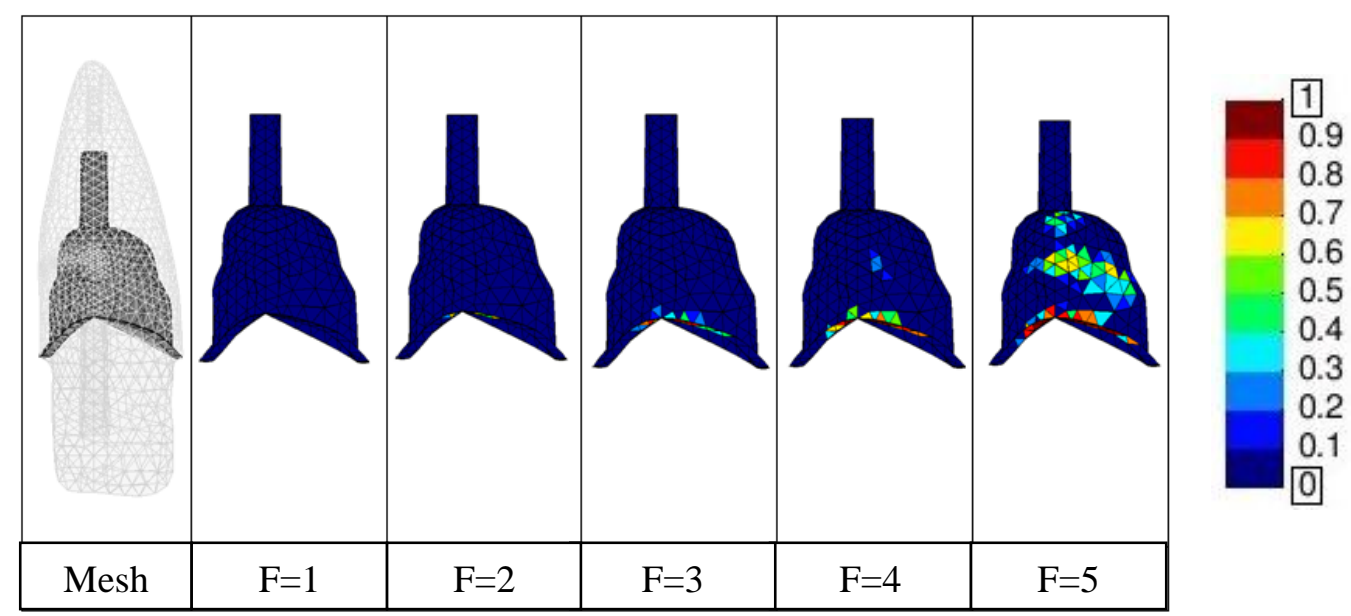

Fig 4.: Damaged interface area. 


\section{CONCLUSIONS}

When weakened roots of endodontically treated teeth are treated with adhesive composite reconstruction and post/core restoration, the results of this study indicate that the risk of tensile damage to the root walls is higher with stronger adhesive interfaces. Apparently, localized failures of the interface corresponding to peak stress areas decrease the risk of damage to the root dentin walls.

\section{Acknowledgements}

The authors acknowledge the support of the Brazilian research agency FAPEMIG (Fundação de Amparo à Pesquisa do Estado de Minas Gerais).

\section{REFERENCES}

[1] Gher Jr M. E., Dunlap R. M., Anderson, M. H., Kuhl, L. V., "Clinical survey of fractured teeth". J. Am. Dent. Assoc. 114, 174-7, 1987.

[2] Sorensen J. A., Martinoff, J. T., "Intracoronal reinforcement and coronal coverage: a study of endodontically treated teeth". J. Prosthet. Dent. 51, 780-4, 1984.

[3] Hussain S. K., McDonald A., Moles D. R., "In vitro study investigating the mass of tooth structure removed following endodontic and restorative procedures". J. Prosthet. Dent. 98, 260-9, 2007.

[4] Lang H., Korkmaz Y., Schneider K., Raab W. H., "Impact of endodontic treatments on the rigidity of the root". J. Dent. Res. 85, 364-8, 2006.

[5] Trope M., Maltz D.O., Tronstad L., "Resistance to fracture of restored endodontically treated teeth". Endod. Dent. Traumatol. 1, 108-11, 1985.

[6] McAndrew R., Jacobsen P.H., "The relationship between crown and post design on root stress - a finite element study”. Eur. J. Prosthodont. Restor. Dent. 10, 9-13, 2002.

[7] Dietschi D., Duc O., Krejci I., Sadan A., "Biomechanical considerations for the restoration of endodontically treated teeth: a systematic review of the literature--Part 1. Composition and micro- and macrostructure alterations". Quintessence Int. 38, 733-43, 2007.

[8] Leary J.M., Jensen M.E., Sheth J.J. "Load transfer of posts and cores to roots through cements". J. Prosthet. Dent. 62, 298-302, 1989.

[9] Johnson M. E., Stewart G. P., Nielsen C. J., Hatton J. F., "Evaluation of root reinforcement of endodontically treated teeth". Oral Surg. Oral Med. Oral Pathol. Oral Radiol. Endod. 90, 360-4, 2000.

[10] Belli S., Eraslan O., Eskitascioglu G., Karbhari V., "Monoblocks in root canals: a finite elemental stress analysis study". Int. Endod. J. 44, 817-26, 2011.

[11] Bonfante G., Kaizer O. B., Pegoraro L. F., do Valle A. L., "Fracture strength of teeth with flared root canals restored with glass fibre posts". Int. Dent. J. 57, 153-60, 2007.

[12] Goncalves L.A., Vansan L. P., Paulino S. M., Sousa Neto M. D., "Fracture resistance of weakened roots restored with a transilluminating post and adhesive restorative materials". J. Prosthet. Dent. 96, 339-44, 2006.

[13] Grandini S., Sapio S., Simonetti M., "Use of anatomic post and core for reconstructing an endodontically treated tooth: a case report". J. Adhes. Dent. 5, 243-7, 2003.

[14] Lui J.L., "Composite resin reinforcement of flared canals using light-transmitting plastic 
posts”. Quintessence Int. 25, 313-9, 1994.

[15] Marchi G. M., Paulillo L. A., Pimenta L. A., De Lima F. A., "Effect of different filling materials in combination with intraradicular posts on the resistance to fracture of weakened roots". J. Oral Rehabil. 30, 623-9, 2003.

[16] Moosavi H., Maleknejad F., Kimyai S., "Fracture resistance of endodontically-treated teeth restored using three root-reinforcement methods". J. Contemp. Dent. Pract., 9, 30-7, 2008.

[17] Zogheib L.V., Pereira J. R., do Valle A. L., de Oliveira J. A., Pegoraro L. F., "Fracture resistance of weakened roots restored with composite resin and glass fiber post". Braz. Dent. J. 19, 329-33, 2008.

[18] Sorensen J.A., Martinoff J.T., "Clinically significant factors in dowel design". J. Prosthet. Dent. 52, 28-35, 1984.

[19] Mattos C. M., Las Casas E. B., Dutra I. G., Sousa, H. A., Guerra, S. M., "Numerical analysis of the biomechanical behaviour of a weakened root after adhesive reconstruction and post-core rehabilitation". J. Dent. 40, 423-432, 2012.

[20] Joshi S., Mukherjee A., Kheur M., Mehta, A., "Mechanical performance of endodontically treated teeth". Finite Elem. Anal. Des., 37, 587-601, 2001.

[21] Al-Omiri M.K., Mahmoud A. A., Rayyan M. R., Abu-Hammad O., "Fracture resistance of teeth restored with post-retained restorations: an overview". J. Endod., 36, 1439-49, 2010.

[22] Dietschi D., Duc O., Krejci I., Sadan, A., "Biomechanical considerations for the restoration of endodontically treated teeth: a systematic review of the literature, Part II (Evaluation of fatigue behavior, interfaces, and in vivo studies)". Quintessence Int., 39, 117-29, 2008.

[23] Peutzfeldt A., Sahafi A., Asmussen E., "A survey of failed post-retained restorations". Clin. Oral Investig., 12, 37-44, 2008.

[24] Cervera M., Oliver J., Manzoli O., "A rate-dependent isotropic damage model for the seismic analysis of concrete dams". Earthquake Eng. Struc., 25, 987-1010, 1996.

[25] Freire S. M., Nishio C., Mendes A de M., Quintao C. C., Almeida M. A., "Relationship between dental size and normal occlusion in Brazilian patients". Braz. Dent. J., 18, 253-7, 2007.

[26] Miguez P. A., Pereira P. N., Atsawasuwan P., Yamauchi, M., "Collagen cross-linking and ultimate tensile strength in dentin”. J. Dent. Res., 83, 807-10, 2004.

[27] Thomsen K. B., Peutzfeldt A., "Resin composites: strength of the bond to dentin versus mechanical properties". Clin. Oral Investig., 11, 45-9, 2007.

[28] Rely X Arc - Adhesive Resin Cement System. [cited 2011 12/15/2011]; Available from: www.3m.com/.../RelyX_ARC_Resin_Cement.pdf

[29] El Mowafy O.M., Watts D.C., "Fracture toughness of human dentin". J. Dent. Res., 65, 677-81, 1986.

[30] Keulemans F., Palav P., Aboushelib M. M., van Dalen A., Kleverlaan C. J., Feilzer A. J., "Fracture strength and fatigue resistance of dental resin-based composites". Dent. Mater., 25, 1433-41, 2009.

[31] Lin C.P., Douglas W.H., "Failure mechanisms at the human dentin-resin interface: a fracture mechanics approach". J. Biomech., 27, 1037-47, 1994.

[32] Cimini Jr C., Gouvêa P. H., Las Casas E. B., Cornacchia T. P. M. "Loads in Teeth - A Critical Review". METMBS'2000: The 2000 International Conference on Mathematics and Engineering Techniques in Medicine and Biological Sciences. Las Vegas, NV: CSREA Press, 2000. 
[33] Barjau-Escribano A., Sancho-Bru, J. L., Forner-Navarro L., Rodriguez-Cervantes P. J., Perez-Gonzalez A., Sanchez-Marin F. T., "Influence of prefabricated post material on restored teeth: fracture strength and stress distribution". Oper. Dent., 31, 47-54, 2006.

[34] Manzoli O. L., Gamino A. L., Rodrigues E. A., Claro G. K. S., "Modeling of interfaces in two-dimensional problems using solid finite elements with high aspect ratio". Comput. Struct., 94-95, 70-82, 2012.

[35] Tang W., Wu Y., Smales R. J., "Identifying and reducing risks for potential fractures in endodontically treated teeth". J. Endod., 36, 609-17, 2010.

[36] Lehman M. L., “Tensile strength of human dentin”. J. Dent. Res., 46, 197-201, 1967.

[37] Craig R. G., Peyton F. A., "Elastic and mechanical properties of human dentin". $J$. Dent. Res., 37, 710-8, 1958.

[38] Albuquerque R de C., Polleto L. T., Fontana R. H., Cimini, C. A., "Stress analysis of an upper central incisor restored with different posts". J. Oral Rehabil., 30, 936-43, 2003.

[39] Coelho C. S., Biffi J. C., Silva G. R., Abrahao A., Campos R. E., Soares C. J., "Finite element analysis of weakened roots restored with composite resin and posts". Dent. Mater. J., 28, 671-8, 2009.

[40] Lanza A., Aversa R., Rengo S., Apicella D., Apicella A., "3D FEA of cemented steel, glass and carbon posts in a maxillary incisor". Dent. Mater., 21, 709-15, 2005.

[41] Sorrentino R., Aversa R., Ferro V., Auriemma T., Zarone F., Ferrari M., Apicella A., "Three-dimensional finite element analysis of strain and stress distributions in endodontically treated maxillary central incisors restored with different post, core and crown materials". Dent. Mater., 23, 983-93, 2007.

[42] Lertchirakarn V., Palamara J. E., Messer H. H., "Patterns of vertical root fracture: factors affecting stress distribution in the root canal". J. Endod., 29, 523-8, 2003.

[43] Naumann M., Preuss A., Frankenberger R., "Load capability of excessively flared teeth restored with fiber-reinforced composite posts and all-ceramic crowns". Oper. Dent., 31, 699-704, 2006.

[44] Zarone F., Sorrentino R., Apicella D., Valentino B., Ferrari M., Aversa R., Apicella A., "Evaluation of the biomechanical behavior of maxillary central incisors restored by means of endocrowns compared to a natural tooth: a 3D static linear finite elements analysis". Dent. Mater., 22, 1035-44, 2006.

[45] Kinney J. H., Marshall S. J., Marshall G. W., 'The mechanical properties of human dentin: a critical review and re-evaluation of the dental literature". Crit. Rev. Oral Biol. Med., $14,13-29,2003$.

[46] Torbjorner A., Fransson B. "A literature review on the prosthetic treatment of structurally compromised teeth”. Int. J. Prosthodont., 17, 369-76, 2004.

[47] De Santis R., Prisco D., Apicella A., Ambrosio L., Rengo S., Nicolais L., "Carbon fiber post adhesion to resin luting cement in the restoration of endodontically treated teeth". $J$. Mater. Sci. Mater. Med., 11, 201-6, 2000.

[48] Spazzin A. O., Galafassi D., de Meira-Junior A. D., Braz R., Garbin C. A., "Influence of post and resin cement on stress distribution of maxillary central incisors restored with direct resin composite". Oper. Dent., 34, 223-9, 2009.

[49] Li L. L., Wang Z. Y., Bai Z. C., Mao Y., Gao B., Xin H. T., Zhou B., Zhang Y., Liu B., "Three-dimensional finite element analysis of weakened roots restored with different cements in combination with titanium alloy posts". Chin. Med. J., 119, 305-11, 2006.

[50] Naumann M., Sterzenbach G., Rosentritt M., Beuer F., Frankenberger R., "Is adhesive cementation of endodontic posts necessary?” J. Endod., 34, 1006-10, 2008.

[51] Mitchell C.A., Douglas W.H., Cheng Y.S., "Fracture toughness of conventional, resinmodified glass-ionomer and composite luting cements". Dent. Mater., 15, 7-13, 1999. 
[52] Saskalauskaite E., Tam L. E., McComb, D., "Flexural strength, elastic modulus, and pH profile of self-etch resin luting cements". J. Prosthodont., 17, 262-8, 2008.

[53] Peutzfeldt A., "Compomers and glass ionomers: bond strength to dentin and mechanical properties". Am. J. Dent., 9, 259-63, 1996.

[54] Asmussen E., Peutzfeldt A., "Long-term fluoride release from a glass ionomer cement, a compomer, and from experimental resin composites". Acta Odontol. Scand., 60, 93-7, 2002.

[55] Holmes D. C., Diaz-Arnold A. M., Leary, J. M., "Influence of post dimension on stress distribution in dentin". J. Prosthet. Dent., 75, 140-7, 1996.

[56] Staninec M., Marshall G. W., Hilton J. F., Pashley D. H., Gansky S. A., Marshall S. J., Kinney J. H., "Ultimate tensile strength of dentin: Evidence for a damage mechanics approach to dentin failure". J. Biomed. Mater. Res., 63, 342-5, 2002.

[57] Naumann M., Metzdorf G., Fokkinga W., Watzke R., Sterzenbach G., Bayne S., Rosentritt M., "Influence of test parameters on in vitro fracture resistance of post-endodontic restorations: a structured review". J. Oral Rehabil., 36, 299-312, 2009. 